\title{
ANALYSES OF PRICE AND INCOME ELASTICITIES FOR CEREALS FOOD CROPS IN AN URBAN TOWN OF KADUNA, NIGERIA
}

\author{
BAL ARABE: A. AHMED B. and CHIKWENDU D. $O$. \\ Department of Agric Economics and Rural Sociology, \\ Ahmadu Bello University /aria
}

\begin{abstract}
The study utilized the extensive data collected on Food Demand and Markets Surveys, undertaken by International Institute for Tropical Agriculture (IITA) in conjunction with Kaduna State Agricultural Development Programme (ADP) between 1999/2000. The objective of the study is to estimate the price and income elasticities of cereals food crops in the study area.

The results of the price and income elasticities of demand suggest that urban households in general are responsive to changes in own price and income in adjusting their consumption patterns. It was shown that the price elasticites for maize, sorghum, millet and rice were -0.6, -0.4, -0.9 and -0.9 respectively, while the expenditure elasticities were 0.6, 0.4, 0.6 and 0.7 for maize, sorghum, millet and rice respectively. The estimates of cross price elasticities suggested that the substitution effects of price changes were not statistically significant for all the cereals.
\end{abstract}

\section{KEYWORDS: Consumption Expenditure, price and cross-price elasticities}

\section{INTRODUCTION:}

Estimating clasticities of consumer demand has been an important research issue in both marketing and applied economics. These estimates help researchers better understand consumer bchaviour and are frequently used to establish firm- or industry-level marketing strategies and appropriate government policies (Chung et al, 2005). The objective of the study is to estimate the price and income elasticities of cereals food crops in the study area.

In Nigeria there is a vast growing internal demand for food and industrial raw materials. In the past most research efforts in the developed and developing countries alike. focused more on the supply side than the demand side. A major problem being faced in Nigeria is the need to improve the quality and availability of agricultural data. Further, the increase in demand for cereals as a result of rapid urbanization means that food crops must increasingly be produced to meet the need of the rural and urban population (Balarabe. 2003).

According to Paulino and Sarma (1988), about 70 percent of the total food crop area harvested in Nigeria was devoted to cereals and the remaining 30 percent to non-cereals. In Kaduna State cereals provide the bulk of caloric intake, the major foods being maize, sorghum and millet.

Consumer expenditure studies have been carried out in a number of countries since 1960. Adesimi and Ladipo (1979) revealed that 35-59 percent of the observed variations in food expenditure in old Western Nigeria was accounted for by income alone. Rogers and Lowdermilk (1991) indicated that total consumption of all foods rises with rising income so that even food whose relative importance decreases with income show increasing absolute consumption.

According to Chesher and Rees (1987) food budget shares were found to fall with 
increasing income partly because of food consumption outside the home. An earlier work by Anthonio (1966) showed that the decline of marginal propensity to consume as income rises signifies a decline in relative expenditure on food as the income rises. Similarly, it has been consistently found that the share of expenditures for staple foods decline with increasing incomes (Eicher and Baker, 1982; Teklu, 1996).

In addition, Hossain and Jensen (2000) research on Lithuania's food demand noted that expenditure elasticities were positive and statistically significant for all food groups. However, Hendricks and Lyne (2003) observed that expenditure elasticities were close to unity for food with staple foods having low elasticities. In the same vein, Waterfield (1985) found that elasticity estimates were higher for luxury products than staples and decreasing with higher incomes.

Attempts to estimate price effects in either a framework of a single demand equal equation or demand system in sub-Saharan Africa, pointed some regularity in patterns. First, the demand for food staples is responsive to changes in relative prices, and second there is a tendency for own-price elasticities to decline in absolute terms as the average income level rise (Teklu, 1996).

Teklu and Johnson (1998), examined demand systems from cross-sectional data in Indonesia and found that uncompensated own price elasticities were negative, meaning that changes in own price indices had inverse impacts on quantities demanded. They also found that, for most groups the elasticity was less than unity except non-fish meat and beans that had elasticities exceeding unity. Rice the staple food was the least responsive to change in own-price.

Earlier studies had revealed that own price elasticities were negative (Waterfield, 1985; Singh and Subramanian. 1986; and Chung et al, 2005). Similarly, estimates of cross-price elasticities indicate that the substitution effects of price changes were quite strong (Singh and Subramanian, 1986; and Ahmed and Shams, 1994).

\section{MATERIALS AND METHODS Study Area}

The study was conducted in Kaduna town, capital of Kaduna State. Kaduna State lies between latitude $9^{\circ} \mathrm{N}$ and $12^{\circ} \mathrm{E}$, with land area of about 46,053 square Kilometers. It is bounded by Katsina and Kano States in the North-north, Niger in the North-west, Nasarawa and Plateau States in the North-east and FCT Abuja in the South-east.

\section{Data Collection}

Secondary data were used for this study. A household survey on "Expenditure and Food Demand Structure of Urban Households" was undertaken by IITA in collaboration with Kaduna, Abuja, Kano, States Agricultural Development Projects (ADPs) from October 1999 to October 2000. The survey was carried out twice in each quarter of the year. Each round was intended to capture the pattem of food demand and consumption at the beginning and at the end of the quarter, to provide data on food and non-food demand with changes in income. A systematic random sampling technique was adopted in order to select respondent household. A sample size of 359 households was used for the study area.

\section{Analytical Tools}

The model was initially fitted to a squared expenditure variable to estimate the elasticities, However, the constant elasticity model was used because its parameters are familiar and easily interpreted as income and price elasticities of demand and has provided the best fit.

To estimate the price and expenditure elasticities the following constant elasticity model was used: $L_{n Q_{1}}=c+b_{1} \operatorname{Ln} Y++b_{2} \operatorname{LnP} 1+b_{3} \operatorname{Ln} P_{2}+b_{4} \operatorname{LnS}+b_{5} \operatorname{LnE}+b_{6} \operatorname{Ln} A+K+e$ 
Where,

$\mathrm{LnQ}_{1}-\log$ ol average per capita monthly quantity of sorghum purchased.

LnY log of average per capita monthly household expenditure, including the imputed value of food from unpaid sources.

$\mathrm{LnP}_{\mathrm{i}} \quad \cdots \log$ of price per $\mathrm{kg}$ of sorghum.

$\mathrm{I}_{\mathrm{nP}} \mathrm{F}_{\mathrm{i}} \quad \log$ of price per $\mathrm{kg}$ of millet

I.nS $\log$ of number of members in the household

InE $\quad$ log of number of years of Education of household head

LnA $=\log$ of Age of the household head

$\mathrm{K} \quad$ "Dummy variable for each cereal which has a value 1 if the household consumed any of the cereals from own production or gifts, 0

otherwise

$\mathrm{e}=$ the error term.

This model was also estimated for the other cereals (Millet, Rice and Maize). To estimate this model. the per capita consumption of the quantity of the cereals purchased was used. Also, per capita monthly expenditure was calculated by adding the values of cereals consumed from own production and gifts to the value purchased and dividing by household members. Estimating the price per kilogramme for each cereal, and computing an average price per household weighted by the quantity purchased at each price calculated prices.

The dependent variable in this equation is the average per capita monthly quantity of maize purchased. This was given as the average monthly quantities purchased and dividing by the household'members.

The per capita monthly expenditure was used as a proxy for income. This was because of the fact that for the bulk of Nigerian low and middle income groups, where the requisite data have been available, there is no much significant saving and so their income and expenditure are practically equal (Aboyade, 1983). It was calculated by adding the values of cereals consumed from own production to the value purchased; this was divided by the household members. On a priori ground this variable would be expected to be positive.

The price per kilogramme for each cereal was estimated by using the average price weighted by the quantity purchased by household. The own price elasticity would be expected to be negative. In terms of cross price elasticity estimates positive sign would be expected for substitutes and negative coefficient for complements.

Household size refers to the number of people who "eat from the same pot", that is take one principal meal together daily and live under common roof. A priori expectation would be a positive coefficient.

Age of the household head is an important characteristic, particularly as it relates to the differential treatment by different age groups in consumption of tood.

Fducation is another important variable, especially in the acquisition of knowledge and skills in different areas of human endeavour. Years of education of the household head may represent efficiency in home production, tastes or the value of time.

\section{Results and Discussions}

The nature of the consumption of cereals can be directly inferred from the coefficients of the parameters in the double-log model. The model was initially fitted to a squared expenditure variable to estimate the elasticities, but the results did not show the expected declining pattern on the expenditure term for all the cereals. This is consistent with the findings of the results obtained by Balarabe (2003), that the rate of increase in absolute quantities consumed does not appear to decline 
with higher income levels for the cereals. Furthermore, because data on food purchases were collected for a single reference weeks in each survey round, some households reported zero consumption of each commodity. This cluster of cases creates a bias in the parameter estimates in OLS regression due to non-normality of the distribution. To correct for this bias the missing values were deleted.

\section{Price Elasticities}

Generally, higher food prices limit the range of food and other commodities that can be purchased, while lower prices permit greater food intake, a wide variety of foodstuffs. and a higher quality diet. The estimated own and cross price elasticities for all the four cereals are presented on Table 1.

\section{Maize}

The estimated own price elasticity for maize (0.69) was shown to be negative and statistically significant at one percent level of probability. This suggests that households respond to changed own price and this means that an increase in the price of maize will results in a decrease in the consumption of purchased maize. For instance, a 10 percent increase in the price of maize will lead to a decrease of less than 7 percent in its consumption. This result conforms to expectation as in some previous studies where the own price was shown to be negative and less than unity (Waterfield, 1985 ). With respect to the cross price elasticities, the results show that the price estimates for millet (5.94) and rice (0.15) were positive and statistically significant at one percent levels of probability. This indicates that they are substitutes to maize. Though the price estimates for sorghum was positive, it was not statistically significant at any level of probability.

\section{Sorghum}

As expected the own price of sorghum $(0.40)$ was observed to be negative and significant at one percent probability level. This also suggests that the households are sensitive to a change in the price of sorghum. The findings further reflect that for example, a 10 percent increase in the price of sorghum can result to less than 4 percent decrease in the consumption of purchased sorghum. The cross price estimates for millet (7.3), indicates that it is a substitute to maize, even though not in a significant way. On the other hands, the estimates for maize $(0.14)$ and rice $(0.13)$ were shown to be negative but insignificant, implying that they are complements to sorghum.

\section{Millet}

The own price estimate for millet (0.88) was shown to be negative and significant at one percent probability level, signifying that a decrease in the consumption of purchased millet would be expected with an increase in its price. This indicates that an increase of say 10 percent will lead to less than 9 percent reduction in consumption of the purchased millet. The positive and significant estimate for sorghum (7.56) price indicates it is a substitute to millet. Conversely, the price estimate of rice $(0.58)$ that was negative and statistically significant at one percent probability level, implied that it is a complement to millet.

\section{Rice}

The negative own price estimate for rice $(0.93)$ is consistent with some previous findings (Waterfield, 1985 and Roger and Lowdermilk, 1991). The result indicates that consumption of purchased rice will decrease with less than 9 percent with a rise in its price. The statistical significance at one percent level of probability of this coefficient implies that the result can be reliably used for policy manipulation. The price of maize (8.98) was shown to have a significant 
cffect as a substitute to rice at one pereent level of probability.

\section{Income Elasticity:}

As expected the expenditure elasticities for all the cereals were posilive and significant at one percent level of probability. The estimates for the income elasticities for the cereals are presented in Table 1. The results further showed that the expenditure elasticities for the four crops were less than unity, which indicate an inelastic condition that implies that the crops are necessities. The estimated elasticities shows that a 10 percent increase in household income would lead to an increase on the consumption of purchased maize, sorghum. millet and rice by less than 6, 4,6 and 7 percents respectively.

\section{Conclusion and Recommendations}

Consumption parameters provide information that guide policy makers in the formulation of food and nutrition policies and programmes. Therefore, predicting the effects of policy change depends on having information on food consumption patterns and demand parameters. Hence, this study reveals that. the own price elasticities estimates for all the cereals were negative. indicating that households in the study arca are responsive to own price changes. This means that all income groups in proportion to the quantities consumed will feel any change in price. Thus, if prices are allowed to rise. the low-income houscholds will be as negatively affected as the high-income houscholds.

Furthermore, the expenditure elasticities estimates for the cereals were all shown to be positive and statistically significant at one percent probability level. This means that households will continue to increase consumption of cereals as their income increase. This suggests that formulating income-generating policies and programmes will encourage higher levels of consumption of these cereals. and therefore. a steady growth in production by enhancing the effective demand.

The positive and significant expenditure elasticities observed in this study means that the Federal government should continue to initiate and sustain both short-run targeted income transfer as well as long-term income-generating programmes that have the capacity to energize a sustainable agricultural development process in the country. Such as provision of credit, infrastructure development, and investments in irrigation and agricultural research programmes.

Table 1: Estimates of own-price, cross-price and income clasticities of cereals

\begin{tabular}{|l|l|l|l|l|} 
Cereals & Maize & Sorghum & Millet & Rice \\
Maize & -0.69 & -0.14 & -8.87 & 8.98 \\
Sorghum & 0.28 & -0.40 & 7.56 & -5.19 \\
Millet & 5.94 & 7.30 & -0.88 & -4.15 \\
Rice & 0.15 & -0.13 & -0.58 & -0.93 \\
Income/Expenditure & 0.57 & 0.36 & 0.62 & 0.72
\end{tabular}

Source: Balarabe, 2003 


\section{REFERENCES:}

Aboyade. O, (1986) Integrated Economics A study of Developing Economies. Addison-Wosley Publishers Itd. London, UK

Adesimi, A.A and Ladipo, O.O (1979) "A quantitative analysis of Short-run houschold food expenditure behaviour in Western Nigeria", Ife Journal of Agriculture 1(2):218-234.

Ahmed. U.A and Shams, Y. 1994 "Demand Elasticities in Rural Bangladesh. "An Applicato" wh" AIDS model", International Food Policy Research Institute, Reprint No, 338:1-25.

Anthonio, Q. B. O. (1966) "Food Consumption and Income Relationship In Nigeria Enge"s Curve Function", Bulletin of Rural Economics and Sociology, $12(1): 52$.

Balarabe. A. S. (2003) "Analysis of Urban Household Consumption of Cereals in Katuma Metropolis of Kaduna State" Unpublished MSc. Thesis, Dept., of Agric. Econs and In Sociology, $\triangle B U$, Zaria.

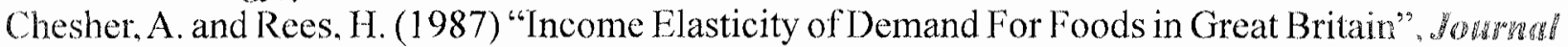
of Agricultural Economics, 38 (3):435-445.

Chung. C. . Dong. D., Schmit, T.M., Kaiser. H.M. and Gould. B.U. (2005)

"Estimation of Price Elasticities from Cross-Sectional Data", Agribusiness 21 (4):565-584.

Eicher, C.K. and Baker, C.D. (1982) Research on Agricultural Development in Sub-Saharan A rrica. Dept. of Agricultural Economics, Michigan State University East Lansing Michigan. U.S.A. Federal Office of Statistics (1997) Annual Abstract of Statistics

llendricks S.L. and Lyne. M.C. (2003) "Expenditure Patterns and Elasticities for Rural Houscholds Sampled in two Communal areas of KwaZulu-Natal", Development Southern Africon 2 f (l):105-127.

Mossain, F. and Jensen, IH.H. (2000) "Lithuania's Food Demand During Fconomic Transition". Agricultural Economics $23(1): 31-40$

Paulino, L. A. and Sarma. J. S. (1988) Analysis of Trends and Projections Food Productions and Consumption in Brazil and Nigeria. International Food Policy Research Institute. Washington D. C. USA.

Rogers, B.L. and Lowdermilk, M. (1991) "Price Policy and Food Consumption in Urban Mali, Ford" Policy $16(6): 461-473$.

Singh. I. and Subramanian. J. (1986) "Agricultural Household Modelling in a Multicrop Environment: Case studies in Korea and Nigeria'In: Singh, L., Squire, L. and Strauss, J. (1986) "Agricultural Household Models-Extension, Application and Policy, Internal Bank for Reconstructional Development/World Bank Washington D.C.. USA.

Tcklu. T. (1996) "Food Demand Studies in Sub-Saharan Africa; A Survey of Empirical Evidence, Food Policy, 21 (6):479-494.

Teklu. T. and Johnson S.R. (1998) "Demand System From Cross-Section Data. An Application to Indonesia" Canadian Journal Of Agricultural Economics 36,(1):83-101.

Watcricld. C. (1985) "Disaggregating Food Consumption Parameters. Designing targetcd nutritional intervention" Food Policy, 10 (4):337-351. 


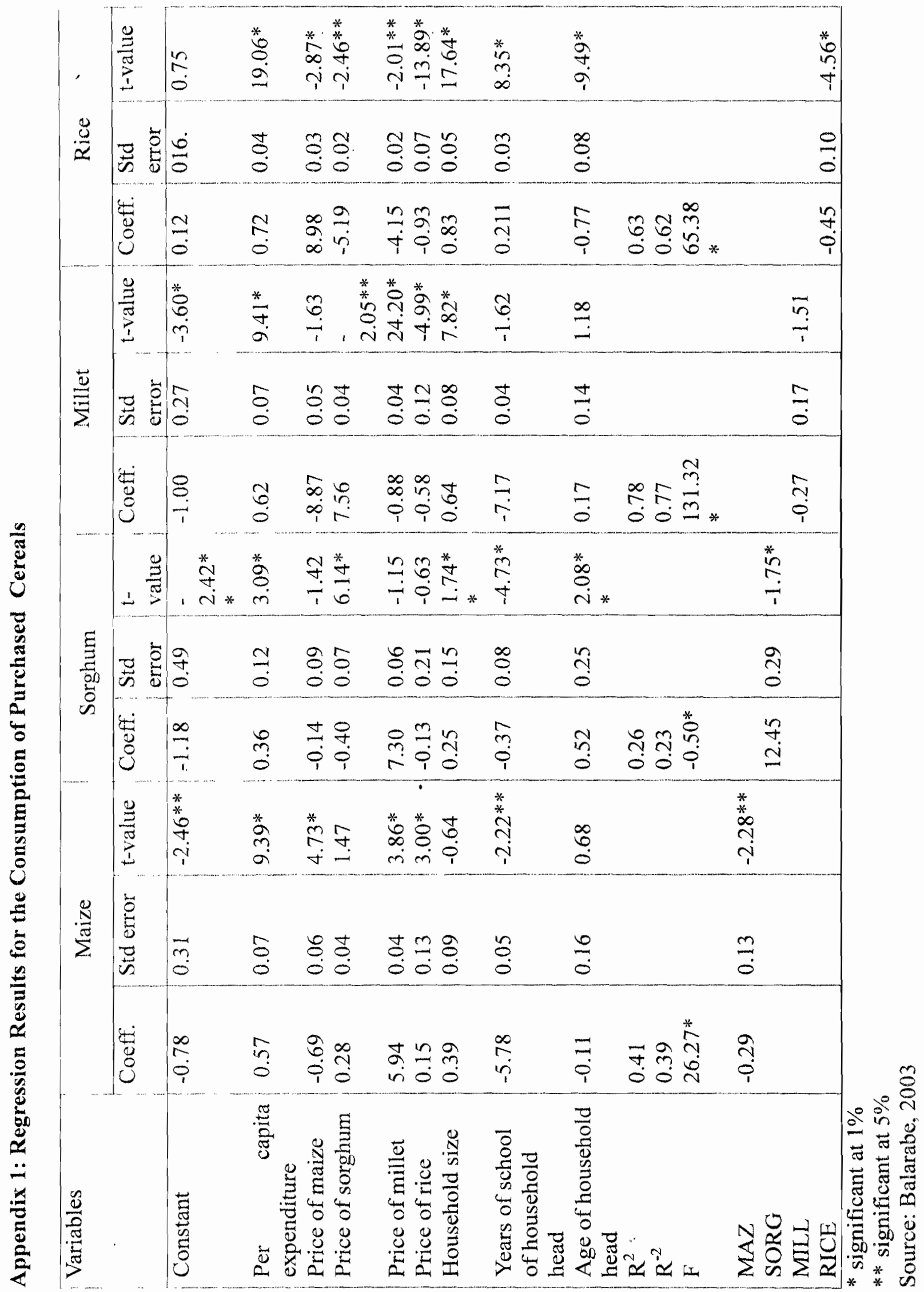

